\title{
Growing up in care: the disempowerment and disenfranchisement of carers
}

\author{
Rhiannon E Evans research fellow \\ Centre for the Development and Evaluation of Complex Interventions for Public Health Improvement (DECIPHer) and Children's Social Care \\ Research and Development Centre (CASCADE), Cardiff University, Cardiff CF10 3BD, UK
}

Kelly presents a powerful narrative of how her perceptions of the healthcare system are viewed through the lens of earlier traumatic experiences. ${ }^{1}$ This compelling account highlights the necessity of practitioners' sensitivity to the histories of those who experience care, but it also raises questions about how professionals interact with and support people charged with the carer role. Birth parents are often given a voice in decision making around their child's health, but the role of "corporate parents" remains ambiguous.

I am currently leading a Health and Social Care Wales study on self harm and suicide in children and young people in care, which is informed by evidence that this population is at increased risk of suicide related outcomes. ${ }^{2}$ Carers have been to the fore in responses to this risk, with the Welsh government's prevention strategy on suicide and self harm acknowledging fostering and adoption agencies as priority care providers. ${ }^{3}$ However, qualitative research with carers has documented their experience of disempowerment and disenfranchisement within the healthcare system, especially with regard to Child and
Adolescent Mental Health Services (CAMHS). Yet many have intimate knowledge of the children they care for, understanding the complex causes and consequences of their health behaviours and outcomes. This is not to suggest that these people's views should be expressed at the expense of those in care, especially where there is clear discord within the caring relationship, but the knowledge that these professionals can bring to the system should not be discounted.

\section{Competing interests: None declared.}

Full response at: http://www.bmj.com/content/352/bmj.i1085/rr-1.

Kelly Á. Growing up in care. BMJ2016;352:11085. doi:10.1136/bmj.i1085 pmid:26984389. 2 Katz LY, Au W, Singal D, et al. Suicide and suicide attempts in children and adolescents in the child welfare system. CMAJ 2011;183:1977-81. doi:10.1503/cmaj.110749 pmid: 22007122.

3 Welsh Government. Talk to me 2: Suicide and self harm prevention strategy for Wales 2015-2020. http://gov.wales/docs/dhss/publications/150716strategyen.pdf

Published by the BMJ Publishing Group Limited. For permission to use (where not already granted under a licence) please go to http://group.bmj.com/group/rights-licensing/ permissions 